\title{
Delivery of Microencapsulated Vitamin D by Using COSMETIC TEXTILES
}

\author{
By \\ Haifa Mubarak Al Anjari \\ Faculty of Home Economics, the Public \\ Authority for Applied Education and \\ Training, Kuwait
}

\section{Research Gournal Specific Fducation \\ Faculty of Specific Education \\ gYansoura University}

ISSUE NO. 42, APRIL. 2016

$$
\text { مجلة بحوث التربية النوعية - جامعة المنصورة }
$$




\section{Delivery of Microencapsulated Vitamin D by Using COSMETIC TEXTILES}

Haifa Mubarak Al Anjari*

\section{Abstract}

With the growing trend in enhancing beauty through healthy means, customers request for apparels and home textiles containing not only their original basic characteristics, such as warmth and comfort, but also ones that carry extra functions, including environmental protection, anti-pollution and most importantly, health and beauty care, in an attempt for a more natural and healthier life.Textile materials with special applications in the cosmetic field have been developed. Currently, microencapsulation technology is rapidly developing in the field of cosmetic textiles because of its benefits and flexibility.

Micro- encapsulation technology is an effective technique to controlthe release properties of active ingredients that prolong thefunctionality of cosmetic textiles.This studydiscusses the using of microencapsulation technique as delivering system in field of cosmetic textiles.

Gelatin microcapsules containing vitamin D were preparedusing emulsion hardening technique. Scanning electron microscopy demonstratedthat the newly developed microcapsules were in the form ofcore-shell spheres with relatively smooth surface. The particlesize of microcapsules ranged from 5.0 to $43.3 \mu \mathrm{m}$. The gelatin micro- capsules were proved to be non-cytotoxic based on theresearch findings of the toxicity studies conducted on humanliver and breast cells.

\section{Introduction:}

A cosmetic textile is a textile article that contains a substance or a preparation that is intended to be released sustainably on to the different superficial parts of the human body, especially the skin, and which claim

* Faculty of Home Economics, the Public Authority for Applied Education and Training, Kuwait 
one (or more) particular properties such as cleansing, perfume, change of appearance, protection, maintenance in good conditioner correction of body odorsdue to the rapid development of technologies, textile materials have also found applications in the cosmetics field in recent years. The textile industry is very optimistic that these products will open up new target groups and sustainable markets(Kan and Yuen 2005). After the prescience of massive knowledge at the medical filed, people were seeking to improve the quality of their life in hygiene and nutrition.

With the growing trend in enhancing beauty through healthy means, customers request for apparels and home textiles containing not only their original basic characteristics, such as warmth and comfort, but also ones that carry extra functions, including environmental protection, anti-pollution and most importantly, health and beauty care, in an attempt for a more natural and healthier life(Holme 2007).

As known that the skin is having large surface area and its consider as one of the largest organ in the body and due to the direct contact with human body and skin for long time, cosmetic textiles are designed to transfer an active substance for cosmetic purposes. One particular example is the transfer of skin moisturising substances. The principle is achieved by simply imparting the cosmetic and pharmaceutical ingredients into the fabric of the clothing so that with the natural movements of the body, the skin is slowly freshened and revitalised. To achieve these functional effects, microencapsulation technology appears as an alternative way to provide satisfactory performance with increased durability (Cheng et al., 2008).

There are a lot of concerns that must be taken in our considerations during this study. The first concern is how we deliver the cosmetic substance under a slow-release delivery mechanism, to avoid overdose.Also there is another concern about the ability of amaterial to perform with an appropriate host response in aspecific application this is known as (biocompatibility), also it should be non-toxic and non-carcinogenic(Achwal 2007).

Micro encapsulation is defined as a technology for the packagingof particles of finely ground solids, droplets of liquids, or gaseousmaterials 
with the help of protective membranes, also called shellor coating. In other meaning, microcapsules are produced by depositing a thin polymer coating on small solid particles or liquid droplets. The core contentsthe active substancemay be released by friction, by pressure, by diffusion through the polymer wall, by dissolution of the polymer wall coating, or by biodegradation. In general, it is used to incorporate food ingredients, enzymes, cells or other materials on a micro metric(Saez, et al., 2007).

During the last few decades, microcapsules have found applications in the production of a wide range of commercial products ,especially in cosmetics and pharmaceuticals because they provides a means of packaging, separating and storing materials on micro scale for later release under controlled conditions.

This technique is being used to develop textiles with newproperties and added value; including climate-controlmaterials, fragrances released fabrics, cosmetic, therapeuticand medical textiles(Kan and Yuen 2005).

Structure ofmicrocapsules (fig.1)are small liquid or solid particles located in center of the particle which is called (core) and it is surrounded by another substance is called (shell) to protect it and separate it to sure the controlled release of the active ingredient outside the core(Hong and Park 2000).

i) Active ingredient: Active ingredient is the substancethat may be in the form of liquid or solid. It is also referred tothe core contents, internal phases, active, encapsulate, payload or filled.

ii) Wall shell : A polymer coating that surrounds the activeingredients which may also be called the wall, shell, externalphase, membrane or matrix. It may be natural polymer, semi- synthetic polymer and synthetic polymer. 


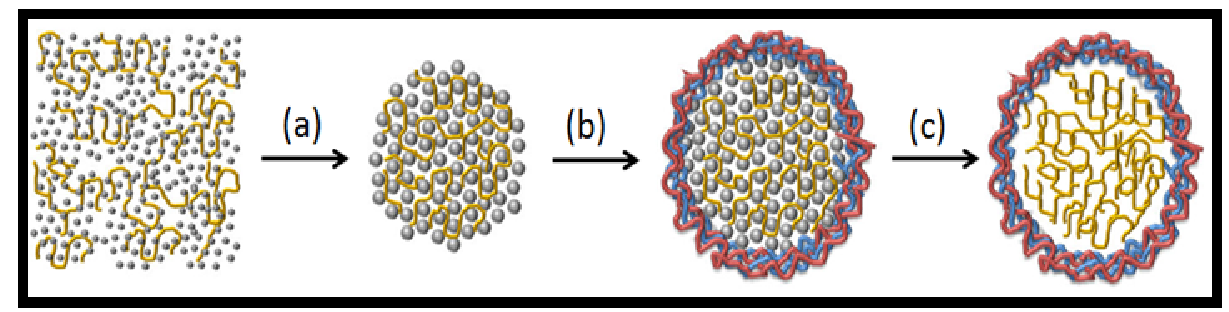

Fig.1: Structure of microencapsulated

Theoretically, microcapsules can be produced with diametersbetween 0.01 and 10,000 microns. The thickness of themicrocapsule wall is generally in the range of 0.5-150 microns.In most cases, the core content of the microcapsule willrepresent between 20 and $95 \%$ of the total mass.

The choice of wall materials depends upon a number offactors such as expected product objectives, nature of the core material, and the process of encapsulation. Table (1) illustrates the typical wallmaterials used for microencapsulation.

The advantages of microencapsulationsince the active ingredient is the most important substance at any industry, so one of major advantage is its ability to protectthe active ingredients from hazardous environment, i.e.oxidation, heat, acidity, moisture or evaporation.It also protects ingredients from interacting with othercompounds in the system, which may result in degradation orpolymerization. Another important advantageis its controlled release properties that seem to bethe best choice for increasing the efficiency of some drugs and minimizationof side effects(Hwang, et al., 2006).

Nowadays, the major interest in microencapsulation iscurrently in the application of vitamins, essential oils, skinmoisturizing agents, skin cooling agents and anti-ageingagents etc. A few studies regarding the techniques ofproducing microcapsules containing cosmetic substanceshave been shown intable (2)( Yamato et al., 1993and Chang, 2005). 


\section{Material and method:}

\section{Material:}

Gelatin and vitamin Dwere obtained from SIGMA Company for Pharmaceutical Industries Cairo, Egypt.

\section{Method:}

Synthesis of gelatin/vitamin D microcapsules and itsapplication on textile materials:

Using the emulsion hardening technique, we prepared gelatin microcapsules containing vitamin $\mathrm{D}$ in our studybydissolving in deionised water at the temperature of 40-60 Cfor $15 \mathrm{~min}$. The solution was then poured into $100 \%$ purecanola oil to form the water in oil emulsion with the aid ofSpan 80 surface-active agent. The mixture was intermixedfor 5 min using a magnetic stir plate, Heidolph MR3001(Heidolph, Germany), at a speed of $1200 \mathrm{rpm}$ to form a stablewater in oil emulsion. The emulsion was then further mixedusing an ultrasonic processor (Vibra Cell ${ }^{\mathrm{TM}}$ VCX 750, Sonicsand Materials Inc., USA) at 300 Watt with the ultrasonicamplitude at $80 \%$ for 1 min to break down the emulsion intosmaller droplets.

The water in oil emulsion was then stirred at $20{ }^{\circ} \mathrm{C}$ whileadding formaldehyde (ACS Reagent, Sigma Aldrich) tocrosslink the microcapsules for $2 \mathrm{~h}$ at $1200 \mathrm{rpm}$. The additionof formaldehyde should be as slow as possible in order tokeep the stability of system. Afterwards, precipitation processwas conducted by adding acetone into the solution. Theaddition of acetone was also aimed at microcapsule separationand dehydration. The precipitates in the form of gelatinmicrocapsules containing vitamin $\mathrm{D}$ were filtered followedby drying at room temperature as shown in Fig. 1. 


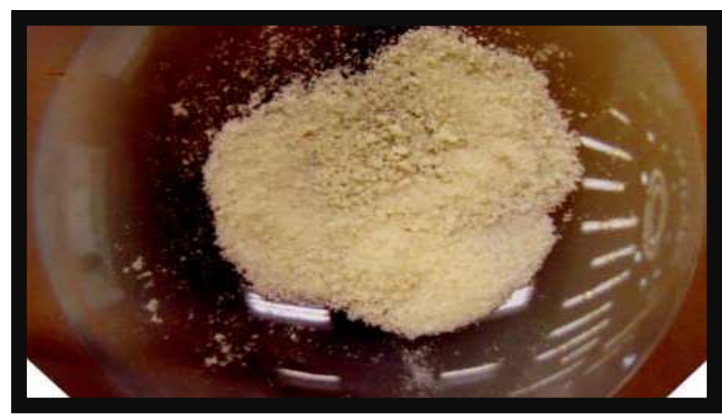

Fig. 1 gelatin / vitamin D microcapsules

\section{Results and Discussion:}

Surface morphology, particle size distribution studies of gelatin/vitamin D microcapsules:

Optical Microscopy and Scanning ElectronMicroscopywere employed to investigate the surface morphology ofmicrocapsules, degree of agglomeration and particle sizedistribution. The mean particle size of microcapsules wasevaluated using a Zetasizer 3000 HAS (Malvern Instruments, UK).

Surface morphology and particle size distribution Fig.2shows the optical micrograph of gelatin microcapsulescontaining vitamin D. The gelatin microcapsules were inspherical form with a certain degree of agglomeration. Fig.3 shows the SEM image of gelatin microcapsules at themagnification of $\times 350$. In agreement with the observationobtained from the optical micrograph, the gelatin micro- capsules appeared to be round in shape with relativelysmooth surface and the particle size of microcapsules wasranging from 5.0 to $43.3 \mu \mathrm{m}$. The result of average particlesize was 24.8 $\mu \mathrm{m}$ as obtained from the particle size analyses.However, a certain degree of agglomeration of microcapsuleswas noted as shown in Fig. 7. The agglomeration of micro- capsules was largely affected by the stirring speed during thecross-linking process. When the stirring speed was too slow, the uncross linked microcapsules could not be entirely separatedand it would be very difficult to separate the microcapsulesonce they combined. Hence, high stirring speed during thecrosslinking process should be maintained in order 
to formthe separated microcap.

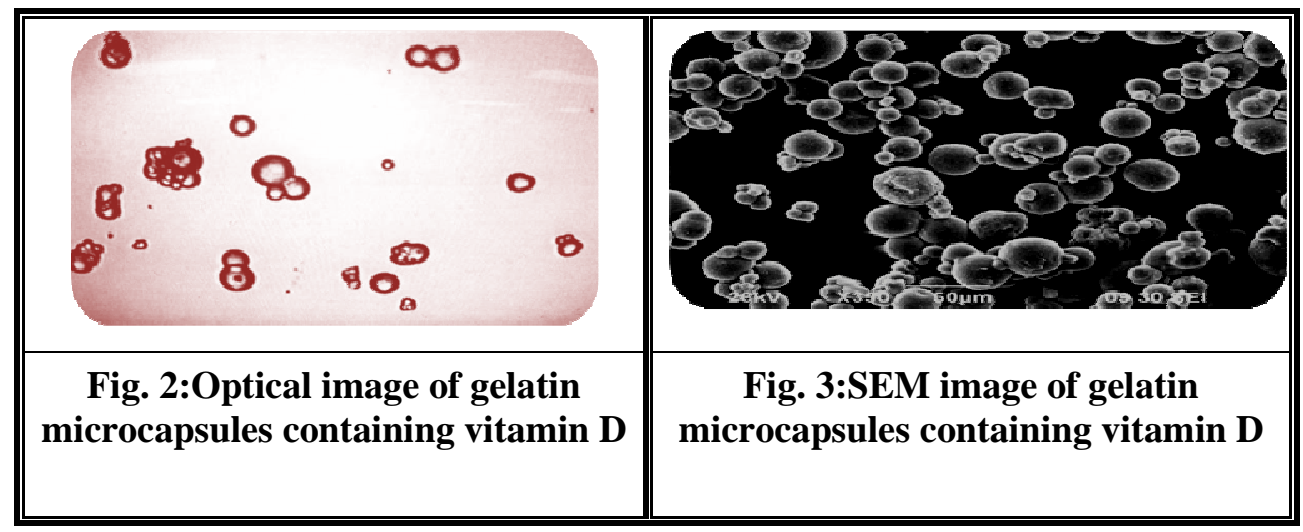

Application of gelatin/vitamin D microcapsules on textilematerials:

Cotton (100\%) fabric samples were cut into manypieces of 20x20 $\mathrm{cm}$. Gelatin microcapsules containingvitamin D were firstly diluted with deionised water at theliquor ratio of 1:10. The solution was stirred for $10 \mathrm{~min}$ usinga magnetic stir plate at a speed of $1200 \mathrm{rpm}$ to obtain a betterdispersion of microcapsules.

Textile binder (Devan Chemicals)was used to enhance the fixation of gelatin microcapsulesonto the cotton fabric. The fabric samples were then immersedinto the microcapsule solution followed by padding using avertical padder at a constant pressure of $1.5 \mathrm{~kg} / \mathrm{cm} 2$ and a speed of $7.5 \mathrm{rpm}$. The wet uptake level of fabric samples was $70 \pm 5 \%$ followed by drying the fabric at room temperature.Fig.4A shows the SEM image of cotton fibersexhibiting the fibrous structure. Fig.4B shows the SEMimage of cotton fibers embedded with the gelatin micro-capsules. The SEM results confirmed that microcapsuleswere successfully padded onto the fiber surface withoutobvious breakage during the padding process. The particlesize of the gelatin microcapsules ranged from 6.7 to 36.7 mwhich was similar to that of the previous SEM evaluation. 


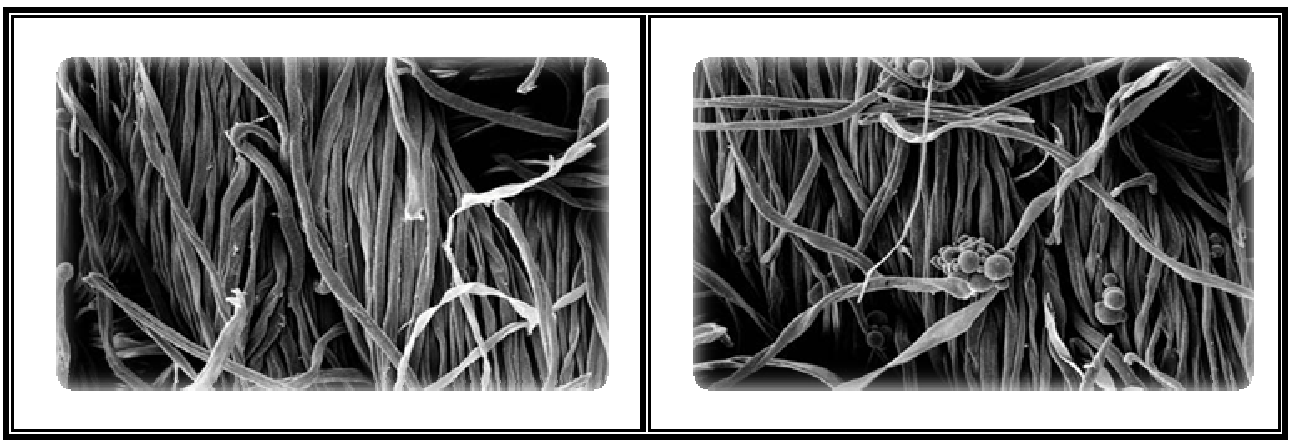

Fig. 4: (A) Control cotton fiber and (B) cotton fiber embedded with gelatin/vitamin D microcapsules.

Vitamin D is a fat-soluble vitamin that is naturally present in very few foods, added to others, and available as a dietary supplement. The use of vitamin $\mathrm{D}$ is known to be beneficial to bone growth and bone remodeling by osteoblasts and osteoclasts(Holick 2006). Vitamin D has other roles in the body, including modulation of cell growth, neuromuscular and immune function, and reduction of inflammation.

The vitamin D substance is releasedfrom the gelatin wall shell in the presence of humidity due toits sensitivity to moisture. A relatively small amount of wateris sufficient to achieve the release, such as the water andsweat present on the surface of the skin. Hence, the releasedvitamin D may be directly be absorbed by the skin( Winzenberg et al., 2011).

\section{Conclusion:}

As can be seen from this brief overview, cosmetic textiles are increasingly expandingconsiderably in the textile industry. Also microcapsules have found numerous application in various branches of the textile industry.In this study, the gelatin microcapsules containing vitamin D were prepared using the emulsion hardening technique andsuccessfully grafted into fibrous materials. This provides apractical example for explaining the development of cosmetictextiles with biological benefits and using it as delivery system for human. 
In spite of the existence of such a broad variety of textile products with microcapsules, there is a lot of space for further improvement and development. The textile industry collaborated with medical profession shouldcontinue to explore and develop functional textiles that fit the consumer needs. We can notice that the merging between the textile industry and medical field is the way for prosperity.

\section{Acknowledgements:}

I would like to acknowledge the pharmaceutical department and biochemical department of the faculty of pharmacy of ASU specially Dr/ Mustafa ahmed for undertaking the researchstudy.

Table I. Typical wall materials used for microencapsulation.

\begin{tabular}{|l|l||}
\hline $\begin{array}{c}\text { Types of wall } \\
\text { material }\end{array}$ & \multicolumn{1}{c|}{ Examples } \\
\hline \hline Natural & $\begin{array}{l}\text { Gelatin, agar, gum, sodium alginate, calcium alginate, fat } \\
\text { and fatty acid, starch, chitosan, casemate, stearm, sucrose, } \\
\text { and wax. }\end{array}$ \\
\hline Semi-synthetic & $\begin{array}{l}\text { Cellulose acetate, cellulose nitrate, ethylcellulose and } \\
\text { hydroxypropylcellulose, methylcellulose, sodium } \\
\text { carboxymethylcellulose, hydrogenated tallow, myristyl } \\
\text { alcohol, dipalmitate, hydrogenated easter oil, glycerylmono-,di, or } \\
\text { tristearate, and 12-hydroxystearyl alchol. }\end{array}$ \\
\hline Synthetic & Acrylic polymer and copolymer. \\
\hline
\end{tabular}


= Delivery of Microencapsulated Vitamin D by Using Cosmetic Textiles

Table 2. Typical core materials used for microencapsulation

\begin{tabular}{|c|c|}
\hline $\begin{array}{c}\text { Types of core } \\
\text { material }\end{array}$ & Examples \\
\hline Solvents & $\begin{array}{l}\text { Benzene, cyclohexane, chlorinated phenyls, } \\
\text { paraffins, esters, ethers, alcohols and water }\end{array}$ \\
\hline Plasticiser & $\begin{array}{l}\text { adipate and pjosphate-type, silicones and } \\
\text { chlorinatedhydrocarbons }\end{array}$ \\
\hline Acids and Bases & Boric acid, caustic alkali and amines \\
\hline Catalysts & $\begin{array}{l}\text { Curing agents, oxidants, free radical initiators and } \\
\text { reducing agents }\end{array}$ \\
\hline Colourants & Pigments and dyes \\
\hline Adhesives & Polysulphides, cyanoacrylates and isocyanates \\
\hline Fragrances & Menthol, essences and speciality compositions \\
\hline Pharmaceuticals & Aspirin, vitamins and amino acids \\
\hline Recording Material & $\begin{array}{l}\text { Reprographic toners, coupling agents, developers, } \\
\text { silver halides, fixing } \\
\text { agents, photochromatic compound, liquid crystals }\end{array}$ \\
\hline
\end{tabular}

\section{References:}

1- Achwal W.B. (2007): Textiles with cosmetic substances. Colourage 50: 41-42.

2- Chang, S.Y. (2005): Process of fabric treatment with natural oil essence microcapsule. US Patent 0257324 A1.

3- Cheng, S.Y, Yuen C.W.M, Kan C.W and Cheuk K.K.L. (2008):

Impartingcosmetic effects on textiles. Colourage 55: 68-78,

4- Holick, M.F. (2006):High prevalence of vitamin D inadequacy and implications for health. Mayo Clin. Proc. 81 (3): 353-73.

5- Holme, I. (2007): Innovative technologies for high performance textiles. Color Technol 123: 59-73,.

6- Hong, K., and Park, S. (2000): Preparation of poly(L-lactide) microcapsules for fragrant fibre and their characteristics. Polymer41: 4567-4572

7- Hwang, J.S., Kim, J.N., Wee, Y.J., Jang, H.G., Kim, S.H. and Ryu, H.W. (2006): Factors affecting the characteristics of melamine resin micro- capsules containing fragrant oils. Biotechnol Bioprocess Eng.11: 391-395. 


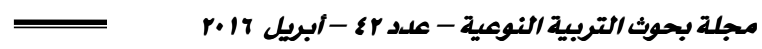

8- Kan, C.W and Yuen, C.W.M. (2005): Cosmetic textiles. Text Asia 36: 29-35.

9- Kan, C.W, Yuen, C.W.M and Lai, O.Y.A. (2005): Aromatherapy in textiles. Text Asia 36: 35-38.

10- Saez, V., Hernandez, J.R. and Peniche, C. (2007): Microspheres as delivery systems for controlled release of peptides and proteins. Biotechnologia Aplicada 24: 108-116.

11- Winzenberg, T., Powell, S., Shaw, K.A., and Jones, G. (2011): Effects of vitamin D supplementation on bone density in healthy children: systematic review and meta-analysis. BMJ 342: c7254

12- Yamato, Y., Yoshida, T., Kikuchi, M., Okamoto, M., Miyoshi, K., Fukuda, S., Fuse, T., Yamauchi, T., Ogawa, Y., Mutagami, S., Shiomura, S., and Mizukami, Y. (1993): Microcapsule, treating liquids containing the same, and textile structure having microcapsules adhering thereto. US Patent 005232769. 


\section{توصيل فيتاهين D عن طريق استخدام هستمضرات المنسوجات التجميلية}

$$
\text { الملخص الصربي }
$$

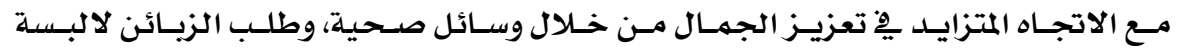

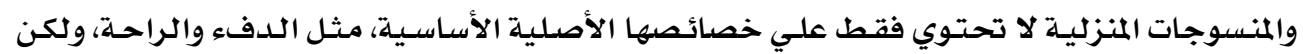

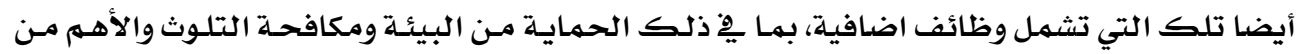

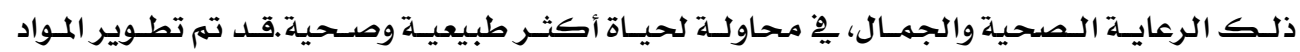

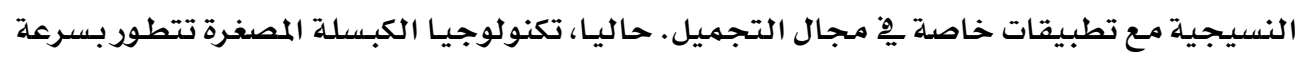

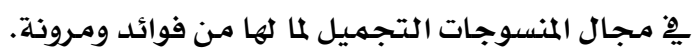

تكنولوجيا الكبسلة المصغرة هي تقنيـة فعالـة للتحكم ِِّ خصائص اطلاق المكونـات النشطة

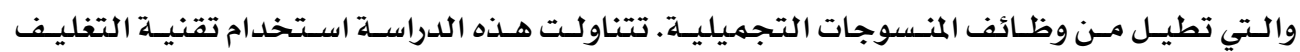

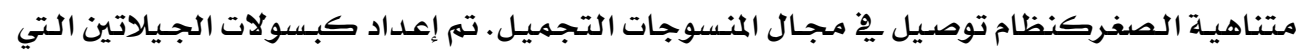

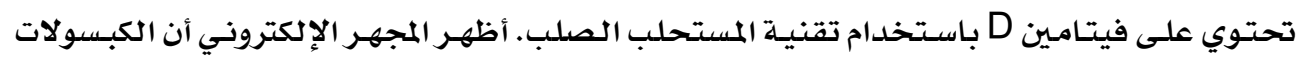

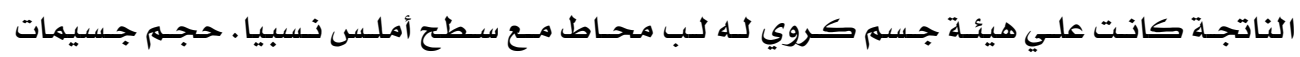

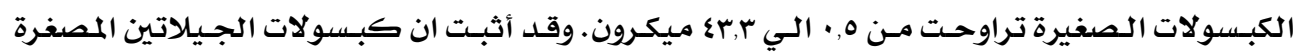

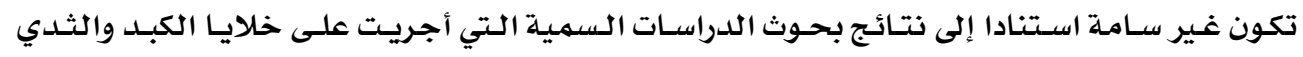
كلإنسان. تكون 